\title{
Pembingkaian Berita Kasus Dugaan Penistaan Pancasila oleh Habib Rizieq Shihab pada Harian Kompas dan Republika
}

\author{
Megi Primagara \\ Program Studi Ilmu Komunikasi FISIP Universitas Muhammadiyah Tangerang \\ Email: eggie168@gmail.com \\ Lisna Agustin \\ Program Studi Ilmu Komunikasi FISIP Universitas Muhammadiyah Tangerang \\ Email: lisnaagustin8@gmail.com
}

\begin{abstract}
ABSTRAK
Penelitian ini dilatarbelakangi oleh pemikiran bahwa setiap media massa memiliki sudut pandang yang berbeda dalam memberitakan sebuah isu atau peristiwa, termasuk pemberitaan kasus dugaan penistaan Pancasila oleh Habib Rizieq Shihab. Penelitian ini bertujuan untuk menjelaskan bagaimana pembingkaian berita mengenai kasus dugaan penistaan Pancasila oleh Habib Rizieq Shihab pada Harian Kompas dan Harian Republika edisi 27 Oktober 2016 - 30 Januari 2017. Teknik analisis penelitian menggunakan model framing Robert N. Entman yang terdiri dari empat tahap: define problem (pendefinisian masalah), diagnose cause (memperkirakan masalah atau sumber masalah), make moral judgement (pembuatan keputusan moral), dan treatment recommendation (penyelesaian masalah). Hasil penelitian ini menunjukkan bahwa pembingkaian berita yang dilakukan Harian Kompas cenderung menonjolkan isi ceramah Habib Rizieq yang diduga menistakan Pancasila dan mencemarkan nama baik Soekarno. Berbeda dengan Harian Kompas, Harian Republika menempatkan Sukmawati sebagai tokoh atau pelaku peristiwa, sementara Habib Rizieq merupakan korban dari upaya kriminalisasi yang dilakukan terhadap ulama.
\end{abstract}

Kata Kunci: Framing, berita, Habib Rizieq, Harian Kompas, Harian Republika

\begin{abstract}
This research is motivated by the idea that every mass media has different perspective in preaching an issue or event, including the news of alleged blasphemy of Pancasila by Habib Rizieq Shihab. This research aims to explain how the framing of news about cases of alleged blasphemy Pancasila by Habib Rizieq Shihab on Harian Kompas and Harian Republika (edition October 27, 2016 - January 30, 2017). The technique of research analysis using Robert N. Entman framing model that consisting of four stages: define problem (pendefinisian masalah), diagnose cause (memperkirakan masalah or sumber masalah), make moral judgement (pembuatan keputusan moral), dan treatment recommendation (penyelesaian masalah). The results of this study indicate the framing news conducted by Harian Kompas inclined to highlight the content of Habib Rizieq's lecture that allegedly deflating Pancasila and defame Sukarno. Unlike Harian Kompas, Harian Republika placed Sukmawati as a character or perpetrator of the incident, while Habib Rizieq was a victim of ulama's criminalization.
\end{abstract}

Keywords: Framing, news, Habib Rizieq, Harian Kompas, Harian Republika

Citation : Primagara, Megi dan Lisna Agustin. (2018). “Pembingkaian Berita Kasus Dugaan Penistaan Pancasila oleh Habib Rizieq Shihab pada Harian Kompas dan Republika". Nyimak Journal of Communication, 2(1): 59-69. 


\section{PENDAHULUAN}

Kasus dugaan penistaan Pancasila yang dituduhkan kepada pemimpin besar Front Pembela Islam (FPI) Muhammad Rizieq bin Hussein Sihab, bermula dari laporan Sukmawati atas isi ceramah Habib Rizieq di lapangan Gasibu Kota Bandung pada 2011. Waktu itu, ceramah Habib Rizieq menyinggung bahwa Pancasila rumusan Soekarno menempatkan Ketuhanan di urutan sila terbawah, sementara Pancasila dalam Piagam Jakarta menempatkan Ketuhanan di urutan sila teratas. Akibatnya, isi ceramah tersebut membuat Sukmawati melaporkan Habib Rizieq ke Bareskrim Polri atas tuduhan pelecehan lambang negara (Pancasila) dan pencemaran nama baik Soekarno sebagai proklamator sekaligus Presiden RI pertama. Per tanggal 30 Januari 2017, berdasarkan keterangan saksi-saksi, Polda Jawa Barat menetapkan Rizieq Shihab sebagai tersangka kasus dugaan penistaan Pancasila.

Peristiwa tersebut pun kemudian ramai diberitakan media massa, termasuk suratkabar nasional Harian Kompas dan Harian Republika. Meskipun keduanya meliput peristiwa yang sama, namun keduanya memiliki sudut pandang berbeda dalam memberitakan kasus tersebut.

Eriyanto (2002: 119) menjelaskan bahwa berita merupakan hasil akhir dari proses kompleks dengan menyortir (memilah-milah), menentukan peristiwa serta tema-tema tertentu dalam suatu kategori tertentu. Hal ini menggambarkan bahwa proses pembuatan berita melibatkan banyak individu yang juga terjadi pada proses penyeleksian dan pembingkaian (framing), baik itu isu, konten maupun informasi yang akan disampaikan kepada masyarakat selaku konsumen media. Sebab itulah, meskipun jurnalis meliput suatu peristiwa di lokasi yang sama dan mewawancarai narasumber yang sama, namun berita yang dipublikasikan bisa jadi berbeda satu sama lainnya. Dalam hal ini setiap media massa akan menggunakan pembingkaian berita menurut sudut pandangnya masing-masing agar suatu peristiwa yang akan diberitakan dapat menjadi lebih bermakna, lebih menarik, dan lebih berarti/lebih diingat. Bahkan, sebuah berita diharapkan dapat menggiring interpretasi khalayak agar bisa sesuai dengan sudut pandang media massa yang bersangkutan tersebut.

Eriyanyo (2002) memaparkan empat efek media massa dalam melakukan pembingkaian (framing) berita. Pertama, pembingkaian (framing) mendefinisikan realitas tertentu dan melupakan definisi lain atas realitas. Framing menyediakan alat bagaimana peristiwa dibentuk dan dikemas dalam bentuk sederhana, mudah dipahami dan dikenal khalayak. Kedua, pembingkaian yang dilakukan media akan menonjolkan aspek tertentu dan mengaburkan aspek lainnya. Ketiga, pembingkaian yang dilakukan media akan menampilkan sisi tertentu dan melupakan sisi lainnya sehingga ada aspek lain (yang mungkin penting) yang tidak mendapatkan liputan pemberitaan. Keempat, pembingkaian yang dilakukan media menampilkan fakta-fakta tertentu dan mengabaikan atau menyembunyikan fakta lainnya. 
Berdasarkan pemaparan singkat di atas, rumusan masalah yang diajukan dalam penelitian ini adalah bagaimana pembingkaian berita tentang kasus dugaan penistaan Pancasila oleh Habib Rizieq Shihab pada Harian Kompas dan Republika edisi 27 Oktober 2016 - 30 Januari 2017. Dengan objek penelitian yang berbeda, perbedaan pembingkaian berita pada Harian Kompas dan Republika juga banyak ditemui dalam berbagai penelitian lainnya (Mayasari, 2017; Mubarok \& Adnjani, 2013; Kosasih dan Prasetyo, 2013; Perdana, Karlinah dan Yudhapramesti, 2012; Junaidi, 2016; Armiah, Rijal \& Falikhah, 2012; Katili \& Yuniarti, 2011; Herayati, Wendra \& Utama, 2016; Muslim, 2013; Herman \& Nurdiansa, 2010; Novianti, 2006; Juditha, 2014) Sementara itu, pembingkaian berita yang menyangkut Front Pembela Islam dan Habib Rizieq Shihab juga bisa ditemui di berbagai penelitian sebelumnya (Andarista, 2017; Pamungkas \& Octaviani, 2017; Bamualim, 2017; Rahmawan, Adiprasetio dan Janitra, 2018; Budiasa, 2017; Priyowidodo, 2010; Suryadinata, 2015; Arif, 2017).

\section{KERANGKA TEORI}

\section{Berita dan Nilai Berita}

Tamburaka (2012: 134-135) menjelaskan bahwa berita adalah hal-hal baru yang merupakan bahan informasi yang bisa disampaikan pada orang lain dalam bentuk berita (news). Tetapi, kebaruan tidak selalu menjadi unsur sebuah peristiwa dapat menjadi berita. Sebuah fakta atau peristiwa yang memiliki 'nilai berita' ialah fakta atau peristiwa yang bisa diolah dan disajikan sebagai berita. Eriyanto (2002: 123) menjelaskan bahwa nilai berita terdiri atas: (1) prominence, yaitu kebesaran atau arti pentingnya suatu peristiwa; (2) human interest, yaitu berkaitan dengan unsur emosional manusia seperti unsur haru, sedih; (3) conflict/controversy, yang berarti peristwa yang mengandung konflik berpotensi menjadi berita; (4) unusual, yang berisi berita tentang peristiwa yang unik; dan (5) proximity, yaitu peristiwa yang memiliki kedekatan dengan khalayak baik secara jarak maupun emosi lebih layak diberitakan.

\section{Analisis Framing}

Sobur (2012: 162) menjelaskan bahwa analisis framing adalah pendekatan yang dipakai guna mengetahui bagaimana perspektif atau cara pandang yang digunakan wartawan ketika menyeleksi isu dan menulis berita. Perspektif tersebut dianggap cukup memengaruhi, mulai dari fakta peristiwa yang diambil, bagian mana yang akan ditonjolkan atau dihilangkan pada konten berita, dan arah pemberitaan berita suatu peristiwa. Pendekatan analisis framing dapat mencermati media massa dalam penggunaan strategi seleksi isu atau fakta, penonjolan, dan keberkaitan fakta ke dalam berita. 


\section{Model Framing Robert N. Entman}

Robert N. Entman adalah salah satu ahli peletak dasar-dasar analisis pembingkaian (framing) untuk studi konten media massa. Eriyanto (2002: 219-220) menjelaskan pandangan Entman mengenai framing, yaitu bagaimana teks komunikasi disajikan dan bagaimana representasi yang ditampilkan secara menonjol bisa memengaruhi khalayak.

Eriyanto menggambarkan konsep framing Entman sebagai proses seleksi isu dan penonjoloan aspek tertentu realitas isi media. Pada seleksi isu, aspek ini berhubungan dengan pemilihan fakta. Dari realitas yang kompleks dan beragam, wartawan memilih aspek tertentu dari suatu isu sehingga proses ini membuat ada bagian isu yang dimasukkan ke dalam berita (included) dan ada sebagian isu yang dikeluarkan (excluded). Penonjolan aspek berhubungan dengan penulisan kata. Ketika aspek tertentu pada suatu peristiwa sudah dipilih maka ia berkaitan dengan pemakaian kata, kalimat, gambar, dan citra tertentu dalam penulisan berita yang nantinya akan dipublikasikan kepada masyarakat.

Analisis framing Robert N. Entman mempunyai model analisis tersendiri. Eriyanto (2002) menjelaskan bahwa model framing Robert N. Entman mempunyai empat tahap: (1) tahap pendefinisian masalah (define problems), yaitu bagaimana media massa mendefiniskan isu/peristiwa sebagai masalah; (2) perkiraan masalah dari sumber masalah (diagnose causes), yaitu tahap media massa menentukan unsur "apa" pada suatu peristiwa atau "siapa" aktor yang dianggap penyebab masalah; (3) tahap pembuatan keputusan moral (make moral judgement), yaitu media massa membuat keputusan moral di balik peliputan dan publikasi sebuah peristiwa/isu; (4) tahap penyelesaian masalah (treatment recommendation), yaitu media massa menawarkan solusi sebagai upaya penyelesaian sebuah masalah berkaitan dengan terjadinya sebuah peristiwa/isu.

\section{METODE PENELITIAN}

Objek penelitian ini adalah pemberitaan tentang kasus dugaan penistaan Pancasila oleh Habib Rizieq Shihab pada Harian Kompas dan Republika edisi 27 Oktober 2016 - 30 Januari 2017. Pemilihan periode penerbitan didasarkan pada dimulainya hari pelaporan Sukmawati atas ceramah Habib Rizieq yang diduga menistakan Pancasila sampai hari penetapan Habib Rizieq sebagai tersangka oleh Polda Jawa Barat.

Penelitian ini menggunakan teknik pengumpulan data dokumentasi untuk mendapatkan sumber data primer. Berdasarkan pendokumentasian berita tentang kasus dugaan penistaan Pancasila Habib Rizieq pada edisi 27 Oktober 2016 - 30 Januari 2017, diperoleh enam (6) berita yang dipublikasikan pada Harian Kompas dan Harian Republika, dengan rincian dua 
(2) berita di Harian Kompas dan empat (4) berita di Harian Republika sebagaimana dapat dilihat pada tabel di bawah ini.

Tabel 1. Jumlah Berita Kasus Dugaan Penistaan Pancasila oleh Habib Rizieq di Harian Kompas dan Republika Edisi 27 Oktober 2016 - 30 Januari 2017

\begin{tabular}{cll}
\hline Nama Media & \multicolumn{1}{c}{ Edisi } & \multicolumn{1}{c}{ Judul Berita } \\
\hline Harian Kompas & 12 Januari 2017 & Rizieq Diperiksa di Polda Jabar \\
& 30 Januari 2017 & $\begin{array}{l}\text { Polda Jabar Tetapkan Rizieq } \\
\text { Shihab Tersangka }\end{array}$ \\
\cline { 1 - 2 } & 12 Januari 2017 & $\begin{array}{l}\text { Rizieq Shihab Merasa } \\
\text { Dikriminalisasi }\end{array}$ \\
& 13 Januari 2017 & Massa Diminta Tak Terprovokasi \\
& 19 Januari 2017 & Kasus Rizieq Shihab Naik \\
& & Penyidikan \\
& 30 Januari 2017 & $\begin{array}{l}\text { Habib Rizieq Tersangka } \\
\text { Penodan Pancasila }\end{array}$ \\
\hline
\end{tabular}

Teknik analisis penelitian menggunakan model framing Robert N. Entman yang terdiri dari empat tahap sebagaimana dijelaskan oleh Eriyanto (2002: 220): (1) define problem (pendefinisian masalah); (2) diagnose cause (memperkirakan masalah atau sumber masalah); (3) make moral judgement (pembuatan keputusan moral); dan (4) treatment recommendation (penyelesaian masalah). 


\section{HASIL DAN PEMBAHASAN}

Hasil analisis terkait enam (6) berita yang didokumentasikan dalam penelitian ini adalah sebagai berikut.

Tabel 2. Tahap Define Problems

\begin{tabular}{|c|c|}
\hline \multicolumn{2}{|c|}{ Define Problems (Pendefinisian Masalah) } \\
\hline $\begin{array}{l}\text { Rizieq Diperiksa di Polda Jabar } \\
\text { (Kompas, } 12 / 01 / 2017 \text { ) }\end{array}$ & $\begin{array}{l}\text { Habib Rizieq diperiksa atas laporan } \\
\text { Sukmawati Soekarnoputri terkait kasus } \\
\text { dugaan penghinaan Pancasila sebagai } \\
\text { dasar negara }\end{array}$ \\
\hline $\begin{array}{l}\text { Polda Jabar Tetapkan Rizieq Shihab } \\
\text { Tersangka (Kompas, 30/01/2017) }\end{array}$ & $\begin{array}{l}\text { Polda Jabar tetapkan Habib Rizieq sebagai } \\
\text { tersangka kasus dugaan penodaan } \\
\text { Pancasila, namun Rizieq tidak ditahan }\end{array}$ \\
\hline $\begin{array}{l}\text { Rizieq Shihab Merasa } \\
\text { Dikriminalisasi (Republika, } \\
\text { 12/01/2017) }\end{array}$ & $\begin{array}{l}\text { Dalam pemeriksaan pertama, Rizieq } \\
\text { Shihab merasa dikriminalisasi oleh } \\
\text { Sukmawati dan penyidik Polda Jabar }\end{array}$ \\
\hline $\begin{array}{l}\text { Massa Diminta Tak Terprovokasi } \\
\text { (Republika, 13/01/2017) }\end{array}$ & $\begin{array}{l}\text { Aksi anarkistis yang terjadi antara dua } \\
\text { ormas, yaitu FPI dan GMBI akibat } \\
\text { terprovokasi dengan beredarnya berita- } \\
\text { berita di medsos }\end{array}$ \\
\hline $\begin{array}{l}\text { Kasus Rizieq Shihab Naik } \\
\text { Penyidikan (Republika, } \\
\text { 19/01/2017) }\end{array}$ & $\begin{array}{l}\text { Habib Rizieq naik tingkat penyidikan, } \\
\text { karena polisi belum menetapkan siapa } \\
\text { tersangka dalam kasus penghinaan } \\
\text { Pancasila }\end{array}$ \\
\hline $\begin{array}{l}\text { Habib Rizieq Tersangka Penodaan } \\
\text { Pancasila (Republika, 30/01/2017) }\end{array}$ & $\begin{array}{l}\text { Setelah Habib Rizieq ditetapkan menjadi } \\
\text { tersangka kasus dugaan penistaan } \\
\text { Pancasila, muncul isu bahwa Rizieq } \\
\text { berselingkuh }\end{array}$ \\
\hline
\end{tabular}


Tabel 3. Tahap Diagnose Cause

\begin{tabular}{ll}
\hline \multicolumn{2}{c}{ Diagnose Cause (Memperkirakan Masalah atau Penyebab Masalah) } \\
\hline $\begin{array}{l}\text { Rizieq Diperiksa di Polda Jabar } \\
\text { (Kompas, 12/01/2017) }\end{array}$ & $\begin{array}{l}\text { Habib Rizieq kurang bersikap kooperatif } \\
\text { selama pemeriksaan }\end{array}$ \\
$\begin{array}{l}\text { Polda Jabar Tetapkan Rizieq Shihab } \\
\text { Tersangka (Kompas, 30/01/2017) }\end{array}$ & Habib Rlzieq Shihab yang menjadi pelaku \\
Rizieq Shihab Merasa & Laporan Sukmawati dan proses hukum \\
Dikriminalisasi (Republika, & yang dilakukan penyidik Polda Jabar \\
12/01/2017) & menyalahi aturan \\
Massa Diminta Tak Terprovokasi & Dua kelompok ormas dari FPI dan GMBI \\
(Republika, 13/01/2017) & yang melakukan aksi keributan \\
Kasus Rizieq Shihab Naik & Polisi yang tidak objektif dan “tebang \\
Penyidikan (Republika, & pilih" dalam memproses laporan dari \\
19/01/2017) & masyarakat \\
Habib Rizieq Tersangka Penodaan & Ada kesan polisi mencari-cari kesalahan \\
Pancasila (Republika, 30/01/2017) & Rizieq
\end{tabular}

Tabel 4. Tahap Make Moral Judgement

\begin{tabular}{ll}
\hline \multicolumn{2}{c}{ Make Moral Judgement (Membuat Keputusan Moral) } \\
\hline $\begin{array}{l}\text { Rizieq Diperiksa di Polda Jabar } \\
\text { (Kompas, 12/01/2017) }\end{array}$ & $\begin{array}{l}\text { Sebagai Warga Negara Indonesia (WNI) } \\
\text { harus menghormati Pancasila sebagai } \\
\text { dasar negara dan Proklamatornya }\end{array}$ \\
$\begin{array}{ll}\text { Polda Jabar Tetapkan Rizieq Shihab } \\
\text { Tersangka (Kompas, 30/01/2017) }\end{array}$ & $\begin{array}{l}\text { Kitab Undang-Undang Hukum Acara } \\
\text { Pidana }\end{array}$ \\
$\begin{array}{ll}\text { Rizieq Shihab Merasa } \\
\text { Dikriminalisasi (Republika, }\end{array}$ & $\begin{array}{l}\text { Sebagai seorang pengagum bukan berarti } \\
\text { tidak boleh melakukan kritik terhadap }\end{array}$ \\
Massa Diminta Tak Terprovokasi & Sesama anak bangsa hanya karena beda \\
(Republika, 13/01/2017) & pendapat tidak harus berujung pada \\
& konflik \\
Kasus Rizieq Shihab Naik & $\begin{array}{l}\text { Integritas kepolisian menjadi pertaruhan } \\
\text { di mata masyarakat dan umat Islam }\end{array}$ \\
Penyidikan (Republika, & \\
19/01/2017) & Indonesia adalah negara hukum. Semua \\
Habib Rizieq Tersangka Penodaan & orang berkedudukan sama dan tidak boleh \\
Pancasila (Republika, 30/01/2017) & diskriminatif dan rekayasa \\
\hline
\end{tabular}


Tabel 5. Tahap Treatment Recommendation

\begin{tabular}{|c|c|}
\hline \multicolumn{2}{|c|}{ Treatment Recommendation (Penyelesaian Masalah) } \\
\hline $\begin{array}{l}\text { Rizieq Diperiksa di Polda Jabar } \\
\text { (Kompas, 12/01/2017) }\end{array}$ & $\begin{array}{l}\text { Dalam proses selanjutnya Polda Jabar } \\
\text { akan mengonfrontasi dengan saksi yang } \\
\text { lain }\end{array}$ \\
\hline $\begin{array}{l}\text { Polda Jabar Tetapkan Rizieq Shihab } \\
\text { Tersangka (Kompas, 30/01/2017) }\end{array}$ & $\begin{array}{l}\text { Habib Rizieq baru menjalani pemeriksaan } \\
\text { sebagai tersangka dengan empat saksi ahli }\end{array}$ \\
\hline $\begin{array}{l}\text { Rizieq Shihab Merasa } \\
\text { Dikriminalisasi (Republika, } \\
\text { 12/01/2017) }\end{array}$ & $\begin{array}{l}\text { Kuasa hukum akan memberikan tesis } \\
\text { Rizieq Shihab kepada penyidik }\end{array}$ \\
\hline $\begin{array}{l}\text { Massa Diminta Tak Terprovokasi } \\
\text { (Republika, 13/01/2017) }\end{array}$ & $\begin{array}{l}\text { Aher meminta seluruh masyarakat } \\
\text { menyerahkan proses hukum terhadap } \\
\text { Habib Rizieq ke kepolisian sebagai aparat } \\
\text { hukum. }\end{array}$ \\
\hline $\begin{array}{l}\text { Kasus Rizieq Shihab Naik } \\
\text { Penyidikan (Republika, } \\
\text { 19/01/2017) }\end{array}$ & $\begin{array}{l}\text { Polisi harus objektif dalam menyikapi } \\
\text { laporan masyarakat }\end{array}$ \\
\hline $\begin{array}{l}\text { Habib Rizieq Tersangka Penodaan } \\
\text { Pancasila (Republika, 30/01/2017) }\end{array}$ & $\begin{array}{l}\text { Penyidik akan meminta keterangan HR } \\
\text { dan F sebagai saksi yang diduga } \\
\text { disebutkan pada konten situs tersebut }\end{array}$ \\
\hline
\end{tabular}

Berdasarkan penjelasan sebagaimana diperlihatkan pada Tabel, 2, 3, 4, dan 5, terlihat bagaimana Harian Kompas dan Republika pada edisi 27 Oktober 2016 - 30 Januari 2017 memberitakan kasus dugaan penistaan Pancasila yang melibatkan Habib Rizieq dengan pembingkaian yang berbeda.

Pembingkaian yang dilakukan oleh Harian Kompas tentang kasus dugaan penistaan Pancasila oleh Habib Rizieq dilakukan dengan menonjolkan isi ceramah Habib Rizieq yang diduga menistakan Pancasila serta mencemarkan nama baik Soekarno. Karena itu, Habib Rizieq menjadi tokoh atau pelaku yang mendorong Sukmawati sebagai korban yang perlu melaporkan ceramah Habib Rizieq kepada pihak kepolisian.

Harian Kompas juga memberitakan kasus tersebut dengan memposisikan Habib Rizieq sebagai warga negara Indonesia yang mempunyai kedudukan sama dalam hukum sehingga harus menjalani proses hukum sebagaimana diatur dalam peraturan perundangan yang berlaku sewaktu seseorang mengalami kasus perkara hukum. Tetapi, pemberitaan Harian Kompas menempatkan Habib Rizieq sebagai warga negara yang bersikap tidak kooperatif selama menjalani proses hukum yang menyangkut dirinya. 
Pembingkaian kasus serupa di Harian Republika berbeda dengan Harian Kompas. Republika lebih menonjolkan isu adanya kekurangpahaman Sukmawati terhadap ceramah Habib Rizieq yang berujung pada upaya kriminalisasi terhadap Habib Rizieq melalui tuntutan hukum dugaan penistaan Pancasila dan pencemaran nama Soekarno sebagai presiden pertama RI. Berbeda dengan Harian Kompas, Harian Republika menempatkan Sukmawati sebagai tokoh atau pelaku peristiwa, sementara Habib Rizieq adalah korban upaya "kriminalisasi ulama".

Karena diposisikan sebagai korban maka pembingkaian berita kasus dugaan penistaan Pancasila di Harian Republika bernuansa "membela" dan membentuk citra positif Habib Rizieq. Hal ini dilakukan dengan lebih banyak memberi ruang narasumber baik kepada pernyataan Habib Riqieq maupun para pendukungnya, seperti kuasa hukum Habib Rizieq (Munarwan), ketua Gerakan Nasional Pengawal Fatwa MUI (Bachtiar Nasir). Selain itu, pemberitaan yang disampaikan juga tidak hanya membahas kasus dugaan penistaan Pancasila sehingga mengaburkan fokus pembaca dalam memahami proses hukum kasus tersebut.

\section{KESIMPULAN}

Pembingkaian berita tentang kasus dugaan penistaan Pancasila oleh Habib Rizieq Shihab di Harian Kompas edisi 27 Oktober 2016 - 30 Januari 2017 menempatkan kasus tersebut sebagai kasus perkara hukum dengan Habib Rizieq sebagai pelaku dan Sukmawati sebagai korban. Karena dibingkai sebagai kasus perkara hukum, Harian Kompas tidak membela Habib Rizieq karena ia diposisikan sebagai warga negara yang berkedudukan sama di hadapan hukum. Sementara itu, pembingkaian berita mengenai kasus dugaan penistaan Pancasila oleh Habib Rizieq Shihab pada Harian Republika edisi 27 Oktober 2016 - 30 Januari 2017 menempatkan kasus tersebut sebagai suatu upaya kriminalisasi terhadap ulama sehingga menempatkan Habib Rizieq sebagai korban yang perlu dibela dari upaya kriminalisasi tersebut.

\section{REFERENSI}

Andarista, Neyna Vandarani. (2017). "Analisis Framing Pemberitaan Chatting Seks Habib Rizieq di Media LIPUTAN6.COM". Spektrum Jurnal Komunikasi, 5(1).

Arie Setyaningrum Pamungkas dan Gita Octaviani. (2017). "Aksi Bela Islam dan Ruang Publik Muslim: dari Representasi Daring ke Komunitas Luring". Jurnal Pemikiran Sosiologi, 4(2): 65-87. 
Arif, Ahmad. (2017). "Dari Represi Politik ke Jeratan Kapital: Praktik Swasensor di Harian Kompas dalam Mewacanakan Toleransi Beragama". Masyarakat Indonesia, 43(2): 165185.

Armiah, Syamsul Rijal dan Nur Falikhah. (2012). "Analisis Framing pada Pemberitaan Tewasnya Osama bin Laden di Harian Republika-Kompas". Alhadharah, Jurnal Ilmu Dakwah, 11(22): 161-173.

Bamualim, C. S. (2011). "Islamic Militancy and Resentment against Hadhramis in Post-Suharto Indonesia: A Case Study of Habib Rizieq Syihab and His Islamic Defenders Front". Comparative Studies of South Asia, Africa and The Middle East, 31(2): 267-281.

Budiasa, M. (2017). “Mediatisasi Aksi Massa Islam 2 Desember 2016”. Jurnal Komunikasi Profetik, 10(1): 35-49.

Eriyanto. (2002). Analisis Framing: Konstruksi, Ideologi, dan Politik Media. Yogyakarta: LKiS. Herayati, Ni Wayan, I Wayan Wendra dan I Dewa Gede Budi Utama. (2016). "Pemberitaan Hubungan Jokowi dengan Megawati dI Media Kompas.com, Republika.co.id, dan Tempo.co: Analisis Framing Robert N. Entman". e-Journal Pendidikan Bahasa dan Sastra Indonesia, 3(5): 1-11.

Herman, Achmad dan Jimmy Nurdiansa. (2010). “Analisis Framing Pemberitaan Konflik Israel - Palestina dalam Harian Kompas dan Radar Sulteng". Jurnal Ilmu Komunikasi, 8(2): 154168

Juditha, Christiany. (2014). "Framing Berita Polemik Lurah Lenteng Agung pada Media Online". Jurnal Penelitian Pers dan Komunikasi Pembangunan, 18(2): 81-102.

Junaidi, Romika. (2016). "Terorisme di Media Baru Indonesia (Analisis Framing Pemberitaan Terorisme di Portal Berita Republika.co.id dan Kompas.com Tahun 2005 -2013)”. KOM \& REALITAS SOSIAL, 12(12): 53-64.

Katili, Kartini Rosmala Dewi dan Tatik Yuniarti. (2011). “Analisis Framing Berita Makelar Kasus di Institusi Kepolisian pada Surat Kabar Kompas dan Republika Edisi 19 - 23 Maret 2010 (Studi Analisis Framing Model Pan dan Kosicki)". Makna, Jurnal Kajian Komunikasi, Bahasa, dan Budaya, 2(1): 1-13.

Kosasih, Fransisca dan Yosep Adi Prasetyo. (2013). "Analisis Framing Berita Kompas, Republika, dan Rakyat Merdeka tentang Peristiwa Ahamadiya di Cikeusik". Jurnal Komunikasi, 5(2).

Mayasari, Silvina. (2017). “Konstruksi Media Terhadap Berita Kasus Penistaan Agama Oleh Basuki Tjahaja Purnama (Ahok): Analisis Framing Pada Surat Kabar Kompas dan Republik". Jurnal Komunikasi, 8(2): 8-18. 
Mubarok dan Adnjani, Made Dwi. (2013). “Konstruksi Pemberitaan Media tentang Negara Islam Indonesia (Analisis Framing Republika dan Kompas)". Jurnal IImiah Komunikasi, $3(1): 25-41$.

Muslim. (2013). “Konstruksi Media tentang Serangan Israel terhadap Libanon (Analisis Framing terhadap Berita tentang Peperangan antara Israel dan Libanon dalam Surat Kabar Kompas dan Republika)". Jurnal Studi Komunikasi dan Media, 17(1): 75-92.

Novianti, Dewi. (2006). "Wacana Media dalam Kasus Bom Bali: Pertarungan Wacana Harian Republika dan Harian Kompas dalam Kasus Bom Bali". Jurnal Ilmu Komunikasi, 4(1).

Perdana, Andhika, Siti Karlinah dan Pandan Yudhapramesti. (2012). “Pemberitaan Front Pembela Islam dalam Majalah Berita Mingguan Tempo". eJurnal Mahasiswa Universitas Padjajaran, 1(1): 1-20.

Priyowidodo, Gatut. (2010). "Reporting on 'Monas Incident' in the Mass Media Construction". Jurnal Ilmu Komunikasi, 8(2): 1-20.

Rahmawan, Detta, Justito Adiprasetio dan Preciosa Alnashava Janitra. (2018). "The Representation of Democracy in Islamic News Sites VOA-Islam and ArRahmah". The Messenger, 10(1): 14-23.

Sobur, Alex. (2012). Analisis Teks Media: Suatu Pengantar untuk Analisis Wacana, Analisis Semiotik, dan Analisis Framing. Bandung: PT. Remaja Rosdakarya.

Suryadinata, M. (2015). “Kepemimpinan Non-Muslim dalam al-Qur'ân: Analisis terhadap Penafsiran FPI Mengenai Ayat Pemimpin Non-Muslim". IImu Ushuluddin, 2(3): 241-253. Tamburaka, Apriadi. (2012). Agenda Setting Media Massa. Jakarta: PT Raja Grafindo Persada. 
